\title{
Telling Stories: A Case Study in Podcasting with Archival Resources
}

\section{By Leigh Rupinski and Jacklyn Rander}

\begin{abstract}
This article is a direct result of the authors' experiences creating a podcast called To The Letter that seeks to engage audiences with archival materials in a unique way. It discusses the goals behind the creation of the podcast, the selection of appropriate content, as well as the logistics of finding collaborators and marketing outlets. Podcasting has grown in popularity in recent years, but little has been studied about the intersection of this popular medium with historical and educational resources. The authors address what worked well, challenges faced, necessary pivots in direction, and subsequent lessons learned throughout the process.
\end{abstract}

\section{Introduction}

Although podcasts have been around since 2004, as an educational genre, they have not been heavily studied by scholars. Former MTV video jockey Adam Curry and software developer Dave Winer are widely credited with developing the concept of podcasts as audio programs made available for automatic download over the Internet. ${ }^{1}$ The term "podcast" itself is a portmanteau word combining "iPod" and "broadcast." Of course, an iPod is not necessary to listen to podcasts anymore; they can be downloaded to any personal media device, typically through Really Simple Syndication (RSS) feeds.

Since then, podcasts have exploded in popularity, with approximately 51 percent of Americans over the age of 12 having listened to one. ${ }^{2}$ Podcast content ranges from current news, celebrity interviews, and parenting advice to television show recaps, nonfiction narratives, and fictional storytelling. Listeners are able to control how and when they consume content, tying into the rise of binge culture. "Binge culture" describes how people may prefer to consume their content all at once, in huge spurts, rather than in small segments.

As podcasts such as This American Life; Serial; Wait, Wait, Don't Tell Me; and How Stuff Works grew in popularity, academic institutions and libraries began to interact with the medium in innovative ways. For example, in 2012 the University of Texas at Austin History Department created its own podcast called 15 Minute History to engage with students and instructors by telling concise historical narratives. ${ }^{4}$ Both the United States Library of Congress and the National Archives of the United Kingdom host podcasts to engage interested audiences with their materials and related stories. ${ }^{5}$ The Library of Congress advertises its over seven unique podcasts with the tagline: "Discover the treasures of the Library through its experts and special guests." Each institution's podcasts are necessarily distinct based on the types of content the archives' contain. 
The appeal of podcasts for special collections and archives comes from their ability to surmount several obstacles that continually plague usage of archival materials. Typically, access to archival materials is limited by location; users must be able to physically travel to the documents to use them. Alternatively, the materials must be digitized to allow access from a distance; however, the ability of institutions to digitize collections depends on funding, specialized equipment, and staff time. For correspondence collections, users may have difficulty reading handwriting without accompanying transcriptions, which take time to produce. Users with visual impairments are restricted even further. Finally, although anyone might find archival materials interesting, many may not ever be prompted to visit an archives to pursue that interest. The authors wished to explore how a podcast might be a way to remove barriers to access and use of one particular collection.

Grand Valley State University Libraries' podcast, To The Letter, had no associated budget and relied on collaboration across multiple university departments for its development. The hosts sought to promote an archival collection by offering a new way to engage with archival materials unimpeded by barriers such as distance, visual impairment, and handwriting interpretation. The podcast offered multiple opportunities for outreach and collaboration, but also faced a number of challenges. It serves as an intriguing case study for other special collections and archives interested in innovative outreach methods and storytelling on a shoestring.

\section{Literature Review}

\section{Creating a Podcast}

Other podcast creators have written extensively on the technology they use to produce and host their podcasts. ${ }^{7}$ These types of how-to articles often provide detailed gettingstarted walkthroughs, equipment analyses, and third-party solutions for production, editing, and hosting. These tutorials apply regardless of the actual podcast content, but their usefulness is highly subjective based on an institution's budgets, needs, and overall vision. How-to articles will help beginner podcasters understand the creation process, but do little to help with curating content, developing institutional workflows, or addressing unique challenges presented by working with archival documents, which will be the primary focus of this article.

\section{Podcasts as Historical Storytelling}

As Christopher Drew notes, "storytelling is an exceptionally longstanding pedagogical style." ${ }^{8}$ Oral histories formed the basis of many early cultures, serving as a means of passing on stories from one generation to the next. Podcasts that focus on building a narrative sustain and transform this tradition.

Narrative podcasting exploded in popularity with Serial, a podcast from the creators of This American Life. Each episode boasted an average of 2.2 million listeners, with the podcast as a whole being downloaded more than 20 million times. ${ }^{9}$ Listeners binged on the real-life story surrounding the murder of Hae Min Lee, growing obsessed with the 
nuances, details, and ambiguity surrounding the case. The power of host Sarah Koenig's storytelling drew them in, taking them along step-by-step on her journey to unravel the stories surrounding whether or not Adnan Syed was responsible for Lee's murder. While Serial stands out as a powerful example of narrative storytelling via podcast, its primary purpose was as a journalistic and entertainment endeavor, not for education.

Serial told one overarching story over the course of multiple episodes. Similarly, educational podcasts, particularly those focused on historical narratives, rely on crafting compelling stories. Christopher Drew identifies this form of a podcast as "The Narrative." He asserts that "the stories in 'The Narrative' genre do more than present new information to the listener or even to merely 'entertain' its audience; the genre's pedagogical importance is in the shaping of stories to teach through the affective power of sound."11 In other words, relaying material through audio creates educational impact.

Educational narrative podcasts seek to make stories more compelling through the application of sound to the content. Podcasts focused on historical storytelling create a unique imagining, or re-creation, of the "experiences of individuals living in times of momentous and terrible events to be shared between host and audience." ${ }^{12}$ This focus on an individual's experiences, rather than a textbook summation, is part of the overall appeal of historical storytelling. Dan Carlin's Hardcore History, an exceptionally popular example of this kind of podcast, is remarkable for its recrafting of history as something anyone can do; it is not limited to academic historians. Salvati argues that within Carlin's podcast he "constructs an experience of the past that is guided both by traditional historiographical tools (primary and secondary sources) and also by a sense of empathy for the people within the stories." ${ }^{13}$ The power of the podcast lies specifically in its ability to tell stories of our shared past in new ways, without the barriers of academic gravitas and professional jargon.

\section{Podcasts as Learning Tools}

Archives are engaging with podcasting both to expose "behind-the-scenes" aspects of archival work and to promote collection materials. The Society of American Archivists' podcast Archives in Context and Ariel Schudson's Archivist's Alley explore archival work itself. These types of podcasts are educational in a different way; they seek to inform the audience about how archives operate, thereby serving as outreach about the profession rather than about the materials themselves. Podcasts such as Colleen Theisen's Historically Yours, however, engage directly with letters found in the University of Iowa's Special Collections. Each episode tells a succinct story based upon a particular letter culled from the collections.

More broadly, academic libraries have adopted podcasts for outreach initiatives in a variety of ways, though little has been done to study how archives and special collections specifically could use podcasts as an engagement tool. Although academic libraries continually leverage new technology and social media to promote their resources, podcasts as a genre remain relatively underutilized. In their 2011 survey, James Bierman and Maura Valentino found that of the 37 libraries studied, 16 created podcasts on how 
to use their resources. ${ }^{14}$ Ten libraries provided podcasts of recorded lectures and events, and eight provided podcasts that included library tours. Five libraries produced podcasts that contained recorded interviews, and three produced podcasts that contained library news or oral histories. ${ }^{15}$ Tanmay De Sarkar's study found that 43 out of 86 libraries used podcasts to conduct a library orientation tour, and 46 out of 83 used podcasts to provide how-to-use tutorials for things like the reading room, reproduction services, and borrowing books. ${ }^{16}$ No mention was made in either study of archives and special collections specifically using podcasts to promote their resources.

De Sarkar further points out that "podcasts are being gradually adopted by libraries to create freely downloadable audio contents and reach out to users, even when they are located a long way from the library building and are busy doing something else." ${ }^{17}$ This speaks to one of the key barriers for users wishing to access archival materials - they must travel or relegate themselves to using only digitized resources. Podcasts, however, provide an opportunity for archivists to reach their users beyond the confines of their physical spaces.

Podcasts function as unique learning tools for students by accommodating their lifestyles and learning preferences. Unlike radio and television programming, podcasts draw on active listening skills; listeners tune in with the explicit intent of focusing on the program from beginning to end. ${ }^{18}$ Podcasts also allow for students in today's "time poor" world to fit learning into their daily routines; "whether the student is commuting, exercising, eating or relaxing the simultaneous use of podcast is usually possible." ${ }^{19}$ This makes a podcast an attractive tool for engaging with undergraduate-aged listeners.

Podcasts are also particularly useful to auditory learners. ${ }^{20}$ Anguelina Popova and Palitha Edirisingha point out that research demonstrates "that audio has educational ability to influence cognition through clarity of instructions, and to influence emotional aspects of learning by conveying immediacy and a connection with the teacher." ${ }^{21}$ Zeynel Cebeci and Mehmet Tekdal build on this idea, stating that "for many people, listening may be more attractive and less tedious than reading. It is well known that human beings have used listening as a primary method for thousands of years in the learning process. Listening may motivate students who do not like reading." 22 They further contend that "podcasting may also be a useful tool in e-learning environments for the visually challenged." 23

\section{Digital Primary Sources, Student Engagement, and Historical Empathy}

Archives and special collections steadfastly promote the importance of primary sources to their users. Archives associated with academic institutions often seek to make connections with related departments, such as history, to encourage use of their materials. Doris Malkmus points out that "faculty unequivocally consider primary sources an essential part of teaching history"; indeed, the majority of faculty members Malkmus studied believed that using primary sources in their instruction was significantly more rewarding than relying on textbooks and lectures. ${ }^{24}$ Thus, faculty members are seeking to stimulate student engagement with intriguing original historical documents, whatever their format, and, thereby, encourage active learning. ${ }^{25}$ 
Despite the good intentions of faculty members, however, undergraduate workers continue to underutilize archival resources. Malkmus concludes that there is "significant potential for increased use of online and archival primary sources to teach undergraduate history. For example, faculty are relatively unaware of which primary sources are available digitally." ${ }^{26}$ In fact, the discoverability of the materials was pointed out as a major barrier to classroom usage. ${ }^{27}$ Podcasts provide an easily discoverable and usable format for students to engage with archival primary sources.

Although humanities faculty members understand the importance of introducing undergraduate students to primary sources, they continue to struggle with how to integrate them effectively into student learning. Thea Lindquist and Holley Long acknowledge the advantages of digital primary sources to potential users, because "they are more accessible, searchable, flexible, and easily manipulated than nondigital formats." ${ }^{28}$ Digital primary sources "also allow maintenance of the documents' archival context, [and the] addition of more description and interpretation." ${ }^{29}$ For busy students who may have little former experience with primary source interpretation, these are valuable benefits.

Lindquist and Long concur with Malkmus's findings that faculty consider primary sources crucial to the undergraduate humanities curriculum. ${ }^{30}$ They further explain that faculty want students to know how to "read primary sources critically; compare sources from different times, places, and perspectives; synthesize sources to make cogent arguments; and recognize recurring themes." ${ }^{31}$ Perhaps more important, "Students also saw advantages to working with primary sources, including feeling a strong sense of connection to the past and a sense of discovery, as well as lending credibility to their arguments. In the case of digital primary sources, students appreciated the convenience of online access and the variety of sources available." 32 The strong sense of connection to the past connects to a key learning goal for many archives-student interactions: build historical empathy and curiosity about the past. Podcasts can serve as a different avenue for students to engage with history in the contexts of their daily lives.

Using physical sources extensively in the classroom can cause issues for nontraditional students, distant learners, or online classes. However, "the reality is that many online digital collections [are] not produced with teaching in mind." ${ }_{33}^{3}$ Students continue to struggle with how to contextualize available primary sources. One undergraduate summed it up concisely: "I would love more background and context for the primary sources I work with." ${ }^{44}$ Undergraduate students may not have the necessary skills built up to find and apply historical context to primary sources found online without guidance.

To build critical thinking skills, students need to be able not only to interact with the sources, but also to understand and engage with the appropriate historical context. Sometimes primary sources by their very nature present barriers to true student engagement. For example, a relevant source may be of no use to a student who cannot interpret the handwriting well enough to get at the content itself. 
Ultimately, while humanities faculty wish to use primary sources, many barriers prevent students from engaging with the materials in meaningful ways. When used with appropriate context and support, however, the benefits of primary sources can be seen in how they serve to fully "illuminate history and its actors and make history come alive for students." 35

\section{Aims and Methodology for Creating a Podcast}

Leigh Rupinski, the archivist for public services and community engagement at Grand Valley State University (GVSU) Libraries, envisioned using a podcast as a means of archival outreach. Inspired by the podcast Historically Yours, ${ }^{36}$ as well as by popular narrative podcasts, she explored the idea of a hosted podcast examining one collection of historical correspondence held at Grand Valley State University Special Collections and University Archives. The essential premise was to focus on one specific collection's story over the course of an episodic series by reading the letters aloud while hosts provided contextual research to supplement the overarching narrative and engage the listener.

By creating a podcast, Rupinski hoped to achieve several goals. At the most basic level, the podcast seeks to provide more exposure for one of the Special Collections and University Archives' interesting, but underutilized, collections. Second, the podcast format experiments with a different way for potential archives users to connect with archival materials. Rupinski imagined that many people unable to make a special trip to the archives might still be interested in the content of the collections themselves, particularly if it's delivered in an easily accessible format. An additional benefit of the auditory content is that it assists students, who frequently struggle with reading cursive handwriting, something Rupinski noticed during class visits. While learning to read primary sources is a valuable skill for historical research, it can be a frustrating barrier to students who simply want to understand and analyze the content. This challenge informed the selection of a handwritten correspondence collection, but no connections were made with any particular curriculum at the outset. If a faculty member expressed interest at a later time, the resource would be available for classroom use, or future seasons can be tailored with their input. Finally, the collaborative opportunities provide potential for the archives to interact with students, colleagues, and other departments on campus in new ways.

Rupinski decided on piloting the podcast with the Joseph P. Olexa Papers, which were donated by a family member to Grand Valley State University in $2015 .{ }^{37}$ The correspondence includes letters between Joe Olexa and his girlfriend, Agnes Van Der Weide, and a variety of one-off letters from various family members and friends. This collection offered a strong storyline, recurring characters, and a familiar setting. The Olexa family lived in Detroit, and Van Der Weide moved to Grand Rapids, Michigan-where one of Grand Valley State University's campuses is located-during the course of the letters. Rupinski hoped the local connection would provide additional appeal to students and the surrounding community. Furthermore, the letters span the duration of World War 
II, a momentous time in American history that would provide plenty of avenues for research to enhance the storytelling experience.

Finally, and perhaps most compelling, Olexa's unpublished memoir, As I Remember, which provides details of his extensive service during the war, accompanies the correspondence. He served in the US Army 26th Infantry Division, Company "L," eventually attaining the rank of staff sergeant. He served from 1940 until the end of the war in 1945, participating in many well-known battles such as the invasion of Normandy, the liberation of Belgium, the Battle of Hürtgen Forest, and the Battle of the Bulge. As the letters mainly focus on the emotional aspects of Joe's relationship with Agnes, this memoir provided the valuable counterpoint of his military experiences, which he often left out of the letters so as not to worry Agnes and to comply with censorship. The combination of letters and memoir provided both a strong narrative focus and an important source for additional context about Olexa's life specifically.

Once a collection was chosen, Rupinski enlisted a cohost, Jacklyn Rander, Publishing Services manager at University Libraries, who was also interested in podcasting. They decided early on to keep Rander in suspense about the story's conclusion, allowing her to act as a stand-in for the listener for more authentic and dynamic back-and-forth discussions and questions. Together, Rupinski and Rander identified a basic format for the podcast. They would serve as hosts, providing contextual information drawn from the memoir and additional research, while a GVSU student would read chosen letters wordfor-word. Rupinski conducted the majority of the historical research, while Rander provided more commentary and questions about the research to act as a stand-in for the listener. Ultimately, each episode was formatted to run between 20 and 30 minutes, including a brief introduction by the hosts followed by the letters and then contextual research about a particular historical topic brought up naturally in the letters' content.

In total, 15 episodes were produced, dealing with everything from morale and wedding traditions to war souvenirs and treatment of injured soldiers. The couple's relationship unfolded over the course of the episodes. Listeners were left in suspense as to whether or not they married and if Olexa survived the war.

\section{Creating a Podcast: A Case Study in Two Parts}

To The Letter took place in two iterations due to unexpected challenges and inadequate preparation. The first, identified here as Take One, provided a solid foundation for the podcast with extraordinarily successful promotional efforts. Ultimately, Rupinski and Rander were forced to put the podcast on hiatus after losing essential collaborative partners. The second iteration of the podcast, Take Two, began after a seven-month production pause as the hosts revised their strategy and established new partnerships. Both iterations provided valuable lessons for the hosts and serve as examples of both what to do and what not to do for other archivists and librarians interested in pursuing podcasting with their collections. 


\section{Take One \\ Collaboration}

Rupinski and Rander created the podcast and served as hosts, but both lacked the technical knowledge to support the full production. In addition, no associated budget existed for a pilot project; therefore, basic hosting sites and support software that charged minimal fees were not feasible options. Rupinski and Rander reached out to a communications faculty member for suggestions on how to get started. He expressed enthusiasm for the idea and committed to acting as audio editor and producer for the podcast. ${ }^{38}$ The production schedule was set on a biweekly basis.

An essential part of the podcast's premise was to bring Joe Olexa's and Agnes Van Der Weide's words to life; accordingly, Rupinski and Rander wanted to use consistent student voices to make it easier for listeners to follow along. The communications faculty member found students within his department who were looking for résumé-building opportunities to provide the voice work, and he managed their recordings. ${ }^{39}$

Depending on the episode's topic, guest hosts were also solicited to provide additional subject knowledge. For example, Lynn Heidelbaugh, a curator at the Smithsonian National Postal Museum, agreed to be interviewed for the episode about how the postal system worked during World War II. ${ }^{40}$ Her expertise was invaluable in providing a clearer understanding of the context surrounding Joe's and Agnes's frequent complaints about delays in mail delivery. Similarly, a Grand Valley State University librarian who held a previous position working with government records about military awards agreed to help host the episode related to that subject. Adding in another voice helped round out the hosts' own research with more direct knowledge.

\section{Technology}

The hosts used a ZoomH4n portable recorder, already owned by University Libraries, to record their segments of the podcast. ${ }^{41} \mathrm{~A}$ larger budget might have supported a more sophisticated piece of equipment, but the Zoom recorder worked well enough in an outof-the-way room, where ambient sounds could be minimized.

Postproduction, the podcast was disseminated via the Special Collections and University Archives WordPress blog accompanied by scans of the original letters. ${ }^{42}$ WordPress integrates with iTunes, Google Play, and Spotify for distribution. Although opportunity was presented for listener feedback in each blog post, and often in the episodes themselves, no comments were received via these avenues. This made it difficult to determine the audience response.

\section{Spreading the Word}

Marketing the podcast turned out to be surprisingly easy within the institution. Rupinski and Rander made connections with the university's communications staff, who agreed to write a short article about the podcast for their weekly publication, GVNow. ${ }^{43}$ The hosts were interviewed and professional photographs of the Olexa Papers 
and podcasting setup were taken as accompanying visuals. Those photographs were helpful additions to multiple promotion efforts, additional articles, and social media posts about the podcast. Following the GVNow article, the student-run newspaper, The Lanthorn, also approached the hosts for an interview. Because both Rupinski and Rander are Grand Valley State University graduates, the podcast was also advertised in the university's alumni e-newsletter. In addition to these publications, the hosts promoted the podcast to their colleagues on the library intranet and relied on subsequent word-of-mouth.

The university-level publicity attracted the attention of Michigan's NPR station, Michigan Radio, which contacted the hosts for an interview on its Stateside program, hosted by Cynthia Canty. ${ }^{45}$ The interview was aired multiple times on Michigan Radio, which led to greater exposure beyond the university.

This initial burst of publicity resulted in approximately 300 downloads on iTunes and the blog for the debut episode in the first month. No other episode would match the page views and downloads of the pilot.

\section{Take Two Collaboration}

The first iteration of the podcast ran into difficulty when the communications faculty member and the student voicing Joe Olexa were unable to continue their commitment to the podcast. ${ }^{46}$ Faced with a number of unfinished episodes and accumulated research, neither Rupinski nor Rander wanted to fully abandon the pilot project and leave listeners wondering about what happened next. While they were both interested in continuing to pursue the original goals of expanding collection exposure, accessibility, and content to users, as well as increasing collaborative opportunities for the archives, they shifted focus to how best to complete the project. None of the original goals could be fully evaluated without the finished product. Still, the original problem of a lack of technical expertise meant they needed to strategize a new approach. Rupinski and Rander consulted with the Digital Studio team, who agreed to take on the editing and production of the podcast at no direct cost to University Libraries. Neither host had been aware of this suite of services available on campus prior to the initial consultation. Editing and production was taken on by an eLearning and Instructional Technology specialist and a student assistant in the Digital Studio, who handled the majority of the audio editing and production work. This was a significant step forward in continuing the story of Joe and Agnes, but new voice actors were still needed to record the letters themselves.

The switch in production partners left the hosts able to reimagine portions of the podcast they were not as pleased with in the first iteration; for example, the Digital Studio found fitting music and recorded cohesive intros and outros. Especially impactful was the Digital Studio's suggestion to recruit new voice actors with a theater background, who might be more able to convey depth and emotional tone. Rupinski used connections 
from previous collaborations with the Music, Theatre, and Dance Department to solicit student recommendations, which resulted in bringing on a recent graduate. Per the Digital Studio's recommendation, the new student also recorded the letters done in previous episodes to ensure listeners could identify with a consistent voice.

There was still a need to fill the voice of Agnes and a few other friends and family members. For the significantly shorter time commitment for these parts, Rupinski and Rander worked with their student employees and colleagues within the library. The ability to communicate directly with all of the voice talent made this process much more efficient than it was in Take One.

\section{Technology}

The Digital Studio's primary role on campus is to provide support for virtual learning services, therefore, it had higher quality equipment available for use. Accordingly, many of the voice actors recorded with the Digital Studio's Blue Yeti USB microphone. ${ }^{47}$ The student production assistant used Audacity, a free open source cross-platform audio software, to record the voice actors. ${ }^{48}$ For editing the content into a cohesive episode, he used Adobe Premiere Pro. ${ }^{49}$

The podcast remained on the Special Collections and University Archives' WordPress blog. The hosts continued to ask for listener feedback, but received no comments; however, several five-star reviews were left on iTunes. Without any commentary to support the ratings, however, evaluating who was listening to or supporting the podcast was impossible.

\section{Spreading the Word}

The second iteration of the podcast was not actively marketed beyond the hosting blog, social media, and University Libraries' intranet. The publications that promoted To The Letter initially, primarily on-campus venues, were not interested in rerunning those stories. Listeners who subscribed to the podcast on iTunes or WordPress during its first run would have received notifications of new episodes.

\section{Evaluation}

After the completion of To The Letter, Rupinski and Rander reviewed what worked well, what could have been improved, and what could be learned from their process. Although Take One and Take Two created a single complete season, the two parts and hiatus made it difficult to evaluate the podcast's overall success quantitatively. The initial excitement within University Libraries for Take One was also reflected more broadly in the university-wide media interest, which in turn led to increased numbers of downloads of the early episodes. Even though Take Two was released on a more consistent schedule, with higher production value, the number of downloads diminished.

The lack of meaningful statistics further complicated formal evaluation. iTunes' Podcast Analytics was created coincident with the podcast and remains in beta at the date of this 
writing. ${ }^{50}$ It was difficult to gather statistics as the interface required specific thresholds before it started capturing data and as the interface itself developed. The hosts could view statistics on the WordPress blog about how many people viewed each post, but those numbers did not account for website visitors who only read the content instead of listening to the audio recordings. WordPress's statistics also did not account for unique versus repeat visitors, which skewed the results. Prior to Take Two, there were no ratings on iTunes; following the completion of the podcast, a number of five-star reviews were left. Although these did not have associated comments, the ratings do suggest listeners were enjoying Take Two.

One of the greatest challenges Rupinski and Rander faced was the loss of momentum caused by the unintended hiatus. The gap also made it more challenging to effectively utilize metrics as measures of success. Initial publicity started the podcast off on a high note, but that interest dwindled significantly during the hiatus. Releasing all the episodes at once, or with minimal gaps between, would likely help sustain momentum and interest. A second season of the podcast could also revitalize interest in the initial content, potentially boosting the download and subscription numbers.

Qualitatively, the hosts received overwhelmingly positive feedback from their colleagues. Several faculty and staff members informally related how much they enjoyed the story and that they referred the podcast to friends and family. Other colleagues were interested in learning more and wanted to collaborate on future episodes by assisting with research or cohosting. The dean of University Libraries promoted the podcast to the board of trustees and at other administration meetings. Rupinski and Rander believe the project was worthwhile because of the level of support and excitement within University Libraries and in the university at large.

One of the greatest benefits of the podcast format overall is its lack of time constraint. Unlike a promotional event, the podcast content is evergreen. Although it required a significant time commitment from the hosts, this was their only major expenditure and it fit into their workload. Even with minimal listener engagement initially, the podcast seemed worthwhile, particularly because interested listeners can stumble upon the episodes at any future point and still find them useful. Once the initial work is invested, it can continue to pay dividends down the road, which is especially useful for potential course integration. Months after the podcast's completion, Rupinski has been able to recommend it to students as a source for research projects and as contextual research for interested student employees working with World War II collections in the archives.

\section{Conclusion}

Throughout Take One and Take Two, Rupinski and Rander were able to learn and make changes as they created a unique and engaging final product. While evaluation of the quantitative success of the podcast ended up being less conclusive than hoped for, the benefits of the podcast format is its continued relevance and the ability to analyze 
success metrics on an ongoing basis. The project also offers multiple takeaways useful to other institutions interested in trying something similar.

Because both Rupinski and Rander were new to podcasting, they scripted out basic dialogue and questions ahead of recording and then did several test run-throughs to make sure the episode flowed well. For the first several episodes, the hosts' demeanor was stilted and they recognized habits of saying "umm," nervously laughing, or repeating the same phrases. Writing an outline and practicing it before recording helped reveal these behaviors and minimize edits in postproduction. Practicing recording allowed the hosts to understand the effects of ambient noise, adjust volume, fine-tune the episode dialogue, and improvise authentically. The practice time was greatly reduced in Take Two, allowing for more efficient recording sessions and less overall time commitment.

Take One suffered from an excess of back-and-forth e-mails and a lack of direct communication. The communications faculty member handled all interactions with the student voicing Joe, making it difficult to provide timely feedback. In Take Two, Rupinski and Rander communicated directly with all the voice actors, which helped establish a shared vision for what they wanted to accomplish by having the letters read word-forword. The students' theatrical background created a more dynamic listening experience.

The time line for distribution of Take One was roughly biweekly, but as Take Two started after such a long break, the hosts decided on a weekly distribution schedule to minimize additional lag times. This approach required several episodes to be prepared up front, but ultimately created a more efficient production workflow. Designing a succinct, focused narrative using fewer episodes supported the quick turnaround time and kept the story interesting for listeners. For a future podcast, Rupinski and Rander believe releasing all the episodes at one time would provide a more cohesive narrative flow and allow binge listening.

A small budget might have alleviated some of the challenges of hosting and producing. Funding can allow the purchase of necessary recording equipment, the compensation of voice actors, and the use of a hosted platform that supports more avenues of distribution, which may in turn boost audience reception. Creating a detailed project plan from the beginning might make advocating for funding easier. Rupinski and Rander believe they would have benefited from establishing expectations for each role, estimates of time commitments, and estimated deadlines for each step of production when communicating with stakeholders.

At the conclusion of the pilot project, Rupinski and Rander considered To The Letter mostly successful in meeting their goals. The podcast provided significant exposure both on and off campus for the Joseph P. Olexa Papers and increased the material's accessibility by making the content available audibly and outside of the physical archives. Likewise, the podcast initiated collaboration opportunities, expanding the archives' engagement. Although reaching these goals was not without struggle, the experience provided valuable insight into how to approach podcasting in the future. 
Both hosts remain enthusiastic about creating another season of To The Letter with a new collection of letters, partnering again with the Digital Studio team, and building on their lessons learned through the initial pilot project.

\section{ABOUT THE AUTHORS}

Jacklyn Rander is the Publishing Services manager at Grand Valley State University Libraries. She earned a BA in hospitality and tourism management from Grand Valley State University and has been working in higher education and libraries for over 12 years. Her areas of interest include library publishing, open access, and open educational resources.

Leigh Rupinski is the archivist for public services and community engagement and History Department liaison librarian at Grand Valley State University Libraries. She earned her MSI from the University of Michigan School of Information and her BA in English from Grand Valley State University. Her areas of interest include primary source instruction, innovative outreach, and the role of storytelling in archival collections.

\section{NOTES}

1. Merriam-Webster, s.v. "podcast," https://www.merriam-webster.com/dictionary/podcast.

2. Felix Richter, “The Steady Rise of Podcasts," March 7, 2019, Statista Infographics, https://www .statista.com/chart/10713/podcast-listeners-in-the-united-states.

3. Christopher Drew, "Educational Podcasts: A Genre Analysis," E-Learning and Digital Media 14, no. 4 (2017): 201-11.

4. 15 Minute History, University of Texas at Austin History Department, https://15minutehistory.org/ about.

5. "Podcasts," Library of Congress, https://www.loc.gov/podcasts; "Podcasts," The National Archives, https://media.nationalarchives.gov.uk/index.php/category/podcasts-2.

6. "Podcasts," Library of Congress.

7. Some examples include Jeff Large, "The Absolute Beginners Guide to Podcasting: Preparation," OSTraining, January 18, 2015, https://www.ostraining.com/blog/podcasting/preparation; Cliff Ravenscraft, "Learn How To Podcast," September 2011, Cliff Ravenscraft, https://mindsetanswerman.com/learn-how-to-podcast; Kevin Lee, "Podcasting for Beginners: The Complete Guide to Getting Started with Podcasts," June 18, 2014, Buffer Marketing Library, https://buffer.com/library/ podcasting-for-beginners; Matthew McLean, "How to Start a Podcast: Every Single Step," June 20, 2018, The Podcast Host, https://www.thepodcasthost.com/planning/how-to-start-a-podcast.

8. Drew, "Educational Podcasts: A Genre Analysis," 206.

9. Sarah Gordon and Shannon Bond, “Serial': Inside a Podcast Phenomenon," December 5, 2014, FT.Com, https://www.ft.com/content/aeb8d37c-7af1-11e4-8646-00144feabdc0.

10. Drew, "Educational Podcasts," 206.

11. Ibid.

12. Andrew J. Salvati, "Podcasting the Past: Hardcore History, Fandom, and DIY Histories," Journal of Radio \&' Audio Media 22, no. 2 (2015): 235.

13. Ibid., 237. 
14. James Bierman and Maura L. Valentino, "Podcasting Initiatives in American Research Libraries," Library Hi Tech 29, no. 2 (2011): 349-58.

15. Ibid., 352.

16. Tanmay De Sarkar, "Introducing Podcast in Library Service: An Analytical Study," VINE: The Journal of Information Knowledge Management Systems 42, no. 2 (2012): 204.

17. Ibid., 191-92.

18. Drew, "Educational Podcasts," 202.

19. Jaya Berk, Sonja Olsen, Jody Atkinson, and Joanne Comerford, "Innovation in a Podshell: Bringing Information Literacy into the World of Podcasting," The Electronic Library 25, no. 4 (2007): 412.

20. Ibid., 411.

21. Anguelina Popova and Palitha Edirisingha, "How Can Podcasts Support Engaging Students in Learning Activities?," Procedia Social and Behavioral Sciences 2 (2010): 5034.

22. Zeynel Cebeci and Mehmet Tekdal, "Using Podcasts as Audio Learning Objects," Interdisciplinary Journal of Knowledge of Learning Objects 2 (2006): 49.

23. Ibid., 49.

24. Doris Malkmus, "'Old Stuff' for New Teaching Methods: Outreach to History Faculty Teaching with Primary Sources," portal: Libraries and the Academy 10, no. 4 (2010): 419.

25. Ibid., 413.

26. Ibid., 414.

27. Ibid., 424.

28. Thea Lindquist and Holley Long, "How Can Educational Technology Facilitate Student Engagement with Online Primary Sources?: A User Needs Assessment," Library Hi Tech 29, no. 2 (2011): 227.

29. Ibid.

30. Ibid., 233.

31. Ibid.

32. Ibid.

33. Ibid., 228.

34. Ibid., 233.

35. Malkmus, “'Old Stuff” for New Teaching Methods," 419.

36. Colleen Theisen, "Historically Yours: A Love Letter to Manuscripts as a Podcast from the Archives," Academic Archivist (blog), July 12, 2017, https://academicarchivist.wordpress.com/2017/07/12/ historically-yours-a-love-letter-to-manuscripts-as-a-podcast-from-the-archives.

37. "Joseph P. Olexa WWII Memoir and Correspondence Collection," Grand Valley State University Special Collections and University Archives, https://gvsu.lyrasistechnology.org/repositories/2/ resources $/ 543$.

38. Len O'Kelly, e-mail to the authors, April 14, 2017.

39. Len O'Kelly, e-mail to the authors, July 31, 2017.

40. Leigh Rupinski, “To The Letter Episode 3: Reading Other People's Mail," October 2, 2017, GVSU Special Collections \& University Archives, https://gvsuspecialcollections.wordpress. com/2017/10/02/to-the-letter-episode-3-reading-other-peoples-mail/.

41. “Zoom H4N," Zoom, 2016, https://www.zoom-na.com/products/field-video-recording/fieldrecording/zoom-h4n-handy-recorder.

42. Leigh Rupinski, “To The Letter Episode 15: The End," September 21, 2018, GVSU Special Collections \& University Archives, https://gvsuspecialcollections.wordpress.com/category/podcast.

43. Matthew Makowski, "New GVSU Podcast Spotlights Historical Letters and the Stories behind the People Who Wrote Them," September 8, 2017, GVNow, https://www.gvsu.edu/gvnow/2017/ new-gvsu-podcast-spotlights-historical-letters-and-the-10125.htm.

44. Tylee Bush, "GVSU Staff, Students Launch WWII Podcast Series," Grand Valley Lanthorn, September 17, 2017, https://lanthorn.com/56033/news/news-gvsu-wwii-podcast. 
45. Stateside Staff, "Grand Valley Brings WW2-Era Letters Back to Life in New Storytelling Project," October 23, 2017, Michigan Radio, NPR, https://www.michiganradio.org/post/grand-valleybrings-ww2-era-letters-back-life-new-storytelling-project.

46. Logan Church, e-mail to authors, February 20, 2018.

47. “Yeti," Blue, 2018, https://www.bluedesigns.com/products/yeti.

48. "Free, Open Source, Cross-Platform Audio Software," Audacity, 2018, https://www.audacityteam .org.

49. "Video Editing That's Always a Cut Above," Adobe, 2018, https://www.adobe.com/products/ premiere.html?promoid=PQ7SQBYQ\&mv=other.

50. “Access Podcast Analytics, Best Practices, and Secure RSS Feed," July 18, 2018, iTunes Connect Resources and Help, https://itunespartner.apple.com/en/podcasts/news/100002358. 